\title{
Understanding the Value of Social Media in the NBA's Digital Communication: A Fan(s)' Perspective
}

\author{
Yann Abdourazakou \\ California State University, Dominguez Hills \\ yabdourazakou@csudh.edu
}

\author{
Xuefei (Nancy) Deng \\ California State University, Dominguez Hills \\ ndeng@csudh.edu
}

\begin{abstract}
Social media (SM) has become sports organizations' most preeminent vehicle to engage with fans and to enhance relationship marketing. Prior studies have mostly focused on the standpoints of sports organizations; less is known about fans' SM experience and perspective. This study focuses on sports fans' SM use during a game, and seeks to understand their popular SM uses and gratifications and the effect of individual characteristics. Informed by the uses and gratifications theory (UGT), we analyze survey data of 400 season-ticket holders of a professional NBA team. Our quantitative data analysis suggests that during a game the NBA sports fans use SM for posting on Twitter \& Facebook, on Instagram \& Snapchat, and checking emails. The less popular uses and gratifications include accessing teams' website, downloading video, and accessing mobile Apps. These usage behaviors varied by individual age, gender and household income. Research contribution and implications are discussed.
\end{abstract}

\section{Motivation: Internet use in the U.S.}

In 2018, 77 percent of Americans owned a smartphone in the United States. According to Cisco [1], there will be 220 million Americans and 2.16 billion smartphones' users worldwide by the end of 2018 with 4.3 devices per person connected to the Internet by 2020. When Pew Research Center began tracking social media adoption in 2005, just 5 percent of American adults used at least one of these platforms [2]. By 2011 that share had risen to half of all Americans, and today 69 percent of the public uses some type of social media.

Social media (SM) has become sports organizations' most eminent vehicle to engage with fans and to enhance team identification. Defined as a group of Internet-based platforms and applications that build on the ideological and technological foundations of Web 2.0., the SM platforms allow the creation and exchange of user-generated content [3]. It makes information instantly obtainable to view, comment on, and share among a large network of users. Social media can be distinguished by six overarching categories, including Wikipedia, blogs, content communities, virtual game worlds, virtual social worlds, and social networking sites [3]. This paper focuses on one type of social media, social networking sites such as Facebook, Twitter, Instagram and Snapchat. Such technology-enabled information and communication capabilities have been increasingly recognized and utilized by sports organizations to enhance their communication strategies and build relationships with their fans. For example, by exploiting the digital communication capabilities of Facebook and Twitter, National Basketball Association (NBA) teams have been delivering relevant sports games' information to their sports followers, thus personalizing their communications [4]. Likewise, social media is also found beneficial for a sports team's branding [5]. As shown in a prior study [6], social media creates a digital proximity between fans and athletes, particularly for those sports figures that use social media to invite interaction and leverage engagement, thus increasing the brand value. Scholars have discussed the numerous opportunities provided by social media for relationship building $[7,8]$.

However, social media strategies implemented by professional sports teams may not always succeed nor fit all segments of the market. For example, two authors examined the relationship between social media addiction and sports fans' identification and commitment, but did not find statistically significant relationship between heavy use of social media and high level of sports identification and commitment [9]. In addition, sports organizations have reported challenges in employing social media capabilities. According to a recent study, the interviews with twenty-six managers of professional sports teams from the four major leagues in North American - MLB, NBA, NFL, and NHL-revealed six objectives for social media use and identified seven challenges of social media as a relationship-marketing medium [10]. As a result of those prior studies, the scholars caution sports organizations about using one-size-fit-all 
approach when designing and implementing their social media-oriented digital marketing strategies.

Moreover, prior studies have mostly focused on the standpoints of sports organizations; less is known about fans' social media use experience and perspective. There is only a partial understanding in the literature as to how sport fans perceive the worth of social media in keeping and improving connections with their favorite sport teams [11]. Yet, it is important for sports management to understand sports fans' experience with and values in digital communications for several reasons. First, such enhanced understanding will not only enable sports organizations to design effective, personalized digital communication [4] but also reach targeted segments of fans to maximize the marketing efforts for fans experience and team commitment [9]. Second, a focus on fans' perspective will complement prior studies from the viewpoints of sports organizations and managers, as sports fans and teams' marketing directors have shown disagreements on the effectiveness of marketing techniques [12]. In the context of widespread social media usage in the age of connected stadiums [13], it has become critical to better understand how sports teams can initiate and sustain a dialogue online, and create more interactivity in the periphery of live games to provide a higher service quality for demanding fans.

This study also aims at contributing to sports communication and relationship marketing literature by suggesting empirical evidence of the fans' needs and wants for sports organizations' digital content from users' standpoint. Our goal is to deliver high-level practical inputs for sports organizations' digital marketing strategies. In particular, this study seeks to answer two critical questions: (1) What are the popular uses and gratifications for sports fans to use social media during a game? (2) How do the uses and gratifications differ by individual characteristics?

To address the questions, we draw upon the uses and gratifications theory (UGT) and analyze survey data collected from season-ticket holders of a professional NBA team based in a large metropolitan city in the west region of United States. Our quantitative data analysis has shown significant findings, including different patterns of digital communications between ticket holders with dissimilar preferences by fans' age, gender and tenure of being a season ticket holder. The originality of this study is twofold: (1) to the best of our knowledge, it is the first study to survey the use of digital communication portfolio (including Facebook, Twitter, Instagram, Snapchat, sports team websites, emails) from sports fans' stance; (2) it provides an in-depth comprehension of digital sports consumption by sports fans' segments characterized by member preferences and individual demographics.

The paper is structured as follows. First, we describe the investigative context with the case of an NBA franchise. It is followed by a literature review on social media marketing in sports management and its drivers, as well as the investigation undertaken to test the conceptual framework. We then present the research site and data collection effort among an NBA franchise. The Findings section presents the results and discusses the implications for sports organization related to digital marketing and the use social media to engage with sports fans. The paper concludes with critical implications, contributions and suggestions for future research.

Below we present the investigative context of NBA and the nature and importance of season ticket holder population.

\section{Investigative context}

\subsection{The National Basketball Association}

The National Basketball Association is a men's professional basketball league in North America, consisting of 30 teams. It is widely considered to be the premier men's professional basketball league in the world. NBA is considered one of the four dominant professional sports leagues in the U.S., beside the other three namely the National Football League (NFL), Major League Baseball (MLB), and the National Hockey League (NHL). As one of the most popular and global sports brand it has grown a strong social media presence. The league is currently the most followed league across Facebook, Twitter, WeChat, Instagram and other social media combined with more than 1.3 billion followers, and the first league ever on SnapChat with a record of 30.1 billion impressions and 4.2 billion video views. On YouTube, the NBA uploads a multitude of videos every day: these videos include highlights, montages, interviews, and talk shows. Though the league trails the NFL in profits, the NBA has profited from the visibility of its celebrities as a differentiating tactic. Players are extensions of their franchise but can also exist alone, as ambassadors of the league, its brand, and its values. The NBA's official Twitter account has more followers (13.8 million) than the NFL's (10.8 million) and the MLB's (4.3 million). The National Hockey League (NHL), for those who are wondering, has 3.3 million followers on its official Twitter account.

The NBA is a very visible sport. Whether it's behind-the-scenes footage on Snapchat or real-time game highlights on Twitter, the league's nonrestrictive policies on sharing video content allow fans to see the 
real personalities of players and teams. A great social media account doesn't just accomplish the goal of keeping you up to date on everything happening with their product, but also makes you feel like you are talking to an authentic person. While the NFL restricts the use of video highlights and markets teams and the league over players, the NBA employs nonrestrictive policies on sharing video online and exposing its players' personalities.

The league has catered to younger fans with an emphasis on social media. It promotes its players, the most famous of whom are the most popular athletes in the country. On Twitter, 25.3 million people follow the NBA's official account, compared to 23.5 million for the NFL. Because of their 'super-team' the Warriors are running very successful social media platforms with 11.3 million followers on Facebook, 5.8 million on Twitter and 8.9 million on Instagram. The current world champion, the 'DubNation' has won 3 championships in its back-to-back last four finals appearances. The team is dubbed as the 'Death Lineup', the 'Splash brothers,' or the 'Hamptons Five'; it almost seems like it comes from a fantasy story. But in terms of raw popularity, the Los Angeles Lakers are the champion. They are the second most successful NBA franchise is history with 16 NBA titles and have been one of the most talked about franchise in 20172018 season with players like Kyle Kuzma and Lonzo Ball. The Los Angeles Lakers even asked the two young stars to tone down social media 'feud' this summer. Off the court, NBA players are easily spotted: some have endorsement deals, more have clothing or lifestyle brands, and almost all have some form of social media. Some athletes, like Lebron James of the Cleveland Cavaliers, have more followers than many sports organizations or sports leagues. Philadelphia 76ers star Joel Embiid is famously entertaining on social media, whether preaching his belief in "The Process” or professing his love for Vampire Diaries.

\subsection{The rise of the "connected" NBA fans}

With smartphones' sales skyrocketing, data sharing behaviors have changed in intensity and scale. In this context, the concept of connected fan is a gamechanger for sports marketing. But like all places of large gatherings, a stadium faces significant technological challenges when 21,000 smartphones are attempting to access the Web at the same time and location [13]. In this context, it is critical for sports teams to be able to satisfy their fans who are always greedy for more data. High-speed Wi-Fi networks have now become one of the main drivers of escalating costs in stadiums' renovation. The race to equip sports arenas with Wi-Fi is growing exponentially in an attempt to match the growing demand owners are facing. Wi-Fi demand is important among millennials' fans, particularly for those interested in college sports teams [14]. If fans can't access the Internet comfortably to post photos to their Instagram accounts, many are simply leaving the stadium [15].

Among the many fans a sports team has, season ticket holders are its financial backbone. Gate receipts account for roughly one-third of total revenue for the MLB teams and NBA teams, with media revenue and venue revenue making up the remainder. The goal of tickets sales department is to convert single-game ticket buyers into multiple-game ticket buyers. Though, understanding customer behavior, satisfaction and loyalty as it relates to sports games are at the core of sports marketing. In today's digital world, sports are no different than any other industry: satisfying a fan's needs online and offline in an arena is largely determined by an organization's capacity to provide relevant mobile Internet services where social media can thrive and build value for the fan base.

Social media also plays a significant, positive role in the NBA's global expansion racking fans in each country as teams go on tour and excite the crowds. An analysis of the top grossing athletes in the world by Forbes last year showed that 18 of the top 100 were basketball players, who together had more than 150 million followers on Facebook. The NBA has recently held games in Mexico City, Shanghai and Barcelona, hoping that building its international fan base will bring in more dollars. In 2017, the NBA announced that it recruited 108 international players from a record 42 countries and territories to enter the league this season, and also signed a \$225 million deal with Rakuten to have a distribution partner in Japan for all live games. The NBA embraces social media, community, mobility and streaming so that geographic location is never the reason why someone becomes a fan. For this reason, the league was an early adopter in embracing social media for players, giving them the ability to share their personal interests.

However, for the growing number of subscriberbased organizations, it can be difficult to understand the factors that really play a role and influence a member's renewal intent. For season ticket-based associations, such as sport clubs, there is usually only a limited pool of supporters from which they can attract members, and thus the retention of members is an issue of particular importance. Understanding fans' specific expectations allows a sports organization to pinpoint and fulfill customer needs.

In this context, social media offers an opportunity for sports organization to interact with fans and to better understand what they need and want in real time. Sports organizations use a variety of platforms to 
communicate with their fans and appear to embrace new platforms as they become available through technology innovation. In the sport context, machines (smartphones), buildings (stadiums and arenas) and consumers interact offline and online: the interaction occurs before, during and after a sport game. For this reason, we have shifted the research focus to fans' use of and expectations for digital communications, and have privileged the literature review on the demand side rather than the strategic and offering side of social media. By doing, so we will build a comprehensive review of the hypothetical gap between what sport fans want and what sports marketers implement.

Below we review the prior literature on social media in sports management and drawn upon the uses and gratifications theory to inform our study.

\section{Theoretical background}

\subsection{Social media use in sports management}

The emergence of social media has profoundly impacted the delivery and consumption of sport. Social media usage is a trend that has developed rapidly in the sport sector over the past decade [16]. Effective media relations and direct communication with customers are essential for all sports organizations because sports fans develop unique and engaging relationships with their favorite teams, both offline and online. Social media research in sport management aligns with a service-dominant logic that an NBA franchise represents and illustrates the role of social media in cultivating relationships among and between brands and individuals. Interaction and engagement play a crucial role in cultivating these relationships [17].

For this reason, successful sports managers must have a clear understanding of how social media operates to implement digital marketing strategies. As a relationship building instrument, social media enables communication and interaction activities between organizations and their stakeholders, thereby emboldening the creation of value [18]. Social media marketing is mostly aimed at engaging an audience through interactive content. In this environment, high levels of fandom, team identification and emotional attachment towards sport clubs have often been associated with the term "engage" in the sport marketing literature [19]. Given the existing fan bases and their level of sport fandom, sports organizations are ideally positioned to benefit from social media as an engagement platform [18, 20].

Nonetheless, there seems to be a lack of substantive effort to know their fan base, and many clubs still struggle with the dilemma of keeping control over their brand, while at the same time building an engaging presence through an empowered fan community [20]. Notwithstanding large investments made, most clubs slowly moved into engaging with supporters via meaningful social media activity. As such, in the sport management literature, research devoted to fan engagement has deserved limited attention [8], particularly on social media [21] and from the fan perspective [22].

Although social media can be used advantageously by sports organizations, scholars call for more studies on social media use in relation to two underexplored areas. First, most of the studies focus on one type of social media platforms-Twitter-and overlook other social media platforms, but in reality, sports teams have used a variety of social media platforms (i.e., Twitter, Instagram, Facebook) to communicate and engage with all their fans. In this regard, it's important for us to examine the use of multiple social media platforms to identify the optimal social media strategies for sports teams to engage and build relationships with their fans. Second, prior studies have adopted a sports organization standpoint, overlooking the needs of sports fans and their expectations for social media communications and interactions. As sports teams increasingly use a variety of social media platforms to communicate with their fans, and as sports fans access social media more frequently, both during games and off games, it has become important for both sports organizations and academia to study the portfolio of social media platforms use and the values perceived by a diversified group of fans. By doing so, we will be able to identify any gap in satisfaction between what organizations think fans want and what fans would like to experience. Such an approach provides an opportunity for sports teams to improve and sustain the engagement and relationship marketing between their organizations and their fan base.

\subsection{Uses and gratifications theory}

Uses and gratifications theory proposes that individuals actively seek out and use specific media to satisfy their specific needs [23]. As such, it became one of the first approaches to consider the active role that audience plays in choosing their media and employing media to meet their specific gratification needs [24]. Unlike the traditional approach of considering media consumers passive, this approach emphasizes individual's free will in making consumption choices about media forms and content. Media consumption includes information benefits, entertainment, economic rewards and social interaction [25].

As UGT posits the active involvement of individual users in their selection of the communication media, 
this theory has been relevant in studies of online media that requires a high level of interactivity from users [26]. According to a literature review of UGT in online media studies [27], consumer choices of online and social media are motivated by four major needs, including need for entertainment, information seeking and information sharing, and desire for remuneration. For example, an empirical study of college students' social media use found that popular uses and gratifications for college students to have Facebook and MySpace accounts include keeping in touch with friends, making new friends and posting/looking at pictures [28].

Based on the UGT perspective, we argue that social media use by fans during a game can be motivated by the needs for information, entertainment, and social interaction. Prior UGT studies [24, 26, 27] have provided evidence to show that individual needs for information and entertainment vary by their age, gender and social economic status (SES) in their choices of mass media and consumption of media content. Informed by prior research, we predict that in the social media context, sports fans' use of social media and other digital channels (including email, website, and mobile apps) will demonstrate different patterns. Moreover, their uses of SM and digital communications will differ by their individual characteristics of age, gender, and household income. Therefore, we hypothesize:

Hypothesis 1: There exists a significant difference in sports fans' in-game use of social media and other digital communication channels.

Hypothesis 2: Individual characteristics of age, gender and household income will have a significant effect on sports fans' in-game use of social media and other digital communication channels.

\section{Research method}

\subsection{Research site and data collection}

The research setting is a NBA team based in a large metropolitan city, and the team is a member of the Western Conference of NBA. The data analyzed and reported in this paper is part of a large survey data collected by the marketing office of the NBA team to understand its fans' overall experience as season ticket holders. The survey included questions about season ticket holders' behavior of in-game digital technology use, including posting on Facebook Twitter, Instagram, Snapchat; sending emails; accessing the team's website; downloading videos and content.

A total data sample of 400 survey responses on the above questions was analyzed and reported in this article. Of the 400 season ticket holders, 118 (29.5\%) of them are half-season ticket holders and 282 (70.5\%) of them are full-season ticket holders. Among all the survey participants in this sample, 76.8 percent are male and 43.3 percent are white/Caucasian. The table below summarizes the demographic characteristics of the 400 season ticket holders of the NBA team.

\begin{tabular}{|l|c|c|c|}
\hline \multicolumn{3}{|c|}{ Bable 1. Sample Characteristics of Season Ticket Members } \\
\hline & $\begin{array}{l}\text { Half- } \\
\text { Season }\end{array}$ & $\begin{array}{l}\text { Full- } \\
\text { Season }\end{array}$ & $\begin{array}{c}\text { Total } \\
\text { (Count) }\end{array}$ \\
\hline \multicolumn{3}{|c|}{ Bender } \\
\hline Female & $44.1 \%$ & $55.9 \%$ & 93 \\
\hline Male & $25.1 \%$ & $74.9 \%$ & 307 \\
\hline \multicolumn{3}{|c|}{ Ethnicity } \\
\hline Asian & $25.6 \%$ & $74.4 \%$ & 82 \\
\hline African-American & $28.2 \%$ & $71.8 \%$ & 39 \\
\hline Hispanic/Latino & $41.8 \%$ & $58.2 \%$ & 67 \\
\hline Native Hawaiian/islander & $44.4 \%$ & $55.6 \%$ & 9 \\
\hline White/Caucasian & $26.0 \%$ & $74.0 \%$ & 173 \\
\hline Other & $30.0 \%$ & $70.0 \%$ & 30 \\
\hline & $29.7 \%$ & $70.3 \%$ & 64 \\
\hline 0_Prefer not to say & $50.0 \%$ & $50.0 \%$ & 28 \\
\hline 1_Under \$50,000 & $33.9 \%$ & $66.1 \%$ & 59 \\
\hline 2_\$50,000-\$99,999 & $29.5 \%$ & $70.5 \%$ & 132 \\
\hline 3_100,000-\$199,999 & $23.9 \%$ & $76.1 \%$ & 71 \\
\hline 4_\$200,000-\$349,999 & $19.6 \%$ & $80.4 \%$ & 46 \\
\hline 5_\$350,000 or more & $70.5 \%$ & 400 \\
\hline Grand Total & $29.5 \%$ & \\
\hline
\end{tabular}

Our main model is estimated using the ordinary least squares (OLS) model for the full data sample. The model includes a fan's number of years as a season ticket holder with the NBA team, type of membership (full-season or half-season), and the five types of digital communication use, including Twitter/Facebook posting, Instagram/Snapchat posting, email checking, accessing sports team website, and video downloading. We also include gender, age, and household income.

\subsection{Distribution of digital channel use}

Our initial data analysis shows that the sports team's fans have demonstrated different patterns of usage with regard to the six categories of digital communications: (1) access team mobile App; (2) downloading/watching video content; (3) posting on Twitter and Facebook; (4) posting to Instagram, Snapchat; (5) access team website; and (6) checking 
emails. Among the six categories, email use was the most popular among the fans, with $52 \%$ of fans checking their emails during the game at least one time, followed by posting on Twitter and Facebook (28.3\%), and posting to Instagram/Snapchat (26.8\%). The distribution is shown in the figure below.

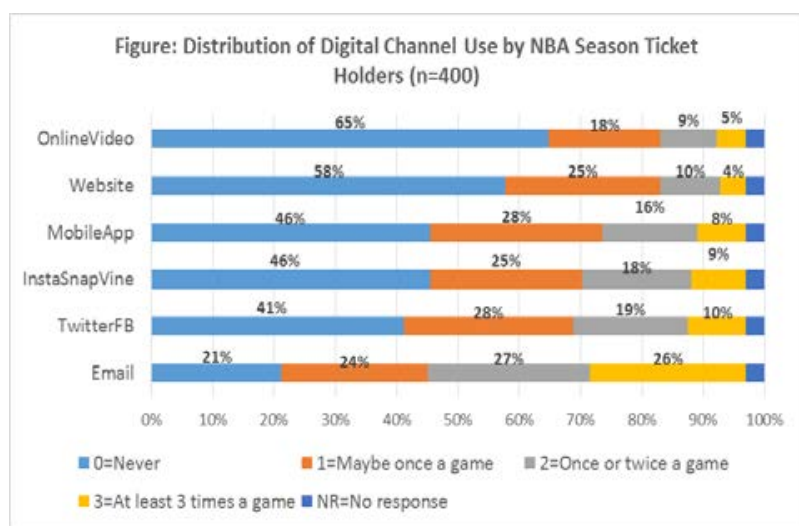

Figure. Distribution of Digital Channel Use

\section{Results}

\subsection{Twitter/Facebook posting during game}

In general, 28.3 percent of the 400 respondents posted at least once on Twitter or Facebook during the game, followed by 27.5 percent of them who made one posting, and 41.3 percent no posting at all during the game. However, the Twitter and Facebook posting behavior differed by the fans' gender, age, and household income. With regard to those who reported at least one posting (including once or twice, or at least three times), the groups include female (32.3\%), 30-39 years old (39.8\%), income less than \$50,000 (39.3\%).

Chi-square analysis of these categorical data has shown the significance of individual characteristics of age, gender, and household income. These differences are reflected in Table 2.

\subsection{Instagram/Snapchat posting during the game}

In general, 26.8 percent of the 400 respondents posted at least once on Twitter or Facebook during the game. As they get older, they are less likely to report Instagram/Snapchat posting. As shown in Table 2, 75.6 percent of those respondents in their 60s or older never made any posts on Instagram/Snapchat. This percentage gradually decreased to 29.1 percent for 30 39 years and 14 percent for $18-29$ years.

\begin{tabular}{|l|l|l|l|l|l|}
\hline \multicolumn{5}{|c|}{ Table 2: Frequency of Twitter/Facebook Posting } \\
\hline & 0 & 1 & 2 & 3 & NR \\
\hline & $31.2 \%$ & $33.3 \%$ & $18.3 \%$ & $14.0 \%$ & $3.2 \%$ \\
\hline Female & $44.3 \%$ & $25.7 \%$ & $18.9 \%$ & $8.1 \%$ & $2.9 \%$ \\
\hline Male & By Age \\
\hline \multicolumn{5}{|c|}{} \\
\hline $18-29$ years & $33.3 \%$ & $42.1 \%$ & $15.8 \%$ & $8.8 \%$ & $0.0 \%$ \\
\hline $30-39$ years & $32.0 \%$ & $25.2 \%$ & $27.2 \%$ & $12.6 \%$ & $2.9 \%$ \\
\hline $40-49$ years & $31.4 \%$ & $35.3 \%$ & $17.6 \%$ & $10.8 \%$ & $4.9 \%$ \\
\hline $50-59$ years & $50.5 \%$ & $20.4 \%$ & $17.2 \%$ & $8.6 \%$ & $3.2 \%$ \\
\hline 60 or older & $75.6 \%$ & $11.1 \%$ & $8.9 \%$ & $2.2 \%$ & $2.2 \%$ \\
\hline & By Household Income \\
\hline No Answer & $54.7 \%$ & $20.3 \%$ & $14.1 \%$ & $7.8 \%$ & $3.1 \%$ \\
\hline Under \$50,000 & $25.0 \%$ & $35.7 \%$ & $14.3 \%$ & $25.0 \%$ & $0.0 \%$ \\
\hline \$50,000-\$99,999 & $30.5 \%$ & $35.6 \%$ & $20.3 \%$ & $10.2 \%$ & $3.4 \%$ \\
\hline \$100,000-\$199,999 & $39.4 \%$ & $25.0 \%$ & $22.0 \%$ & $12.1 \%$ & $1.5 \%$ \\
\hline \$200,000-\$349,999 & $47.9 \%$ & $26.8 \%$ & $19.7 \%$ & $4.2 \%$ & $1.4 \%$ \\
\hline \$35,000+ & $41.3 \%$ & $30.4 \%$ & $15.2 \%$ & $2.2 \%$ & $10.9 \%$ \\
\hline Grand Total & $41.3 \%$ & $27.5 \%$ & $18.8 \%$ & $9.5 \%$ & $3.0 \%$ \\
\hline
\end{tabular}

As shown in Table 3, on average, women reported more posting on Instagram/Snapchat than men, with 33.3 percent and 24.7 percent respectively. Finally, 53 percent of those with household income at $\$ 50,000$ or less reported at least one posting on Instagram/Snapchat, compared to fans from other income categories. Chi-square analysis has shown the significance impact of individual characteristics of age, gender, and household income. The distribution is shown in Table 3.

\subsection{Email checking during the game}

Email checking is more popular than that of Twitter/Facebook posting. On average, 52 percent of all members in the data sample checked email once or twice, or at least 3 times in a game. Among respondents from different age groups, those in 30-39 and 50-59 age categories reported higher frequency of email checking, with 65 percent and 50.6 percent respectively reporting at least one email checking during a game. Among members with different household income, those earning $\$ 200,000$ or more reported a higher percentage of at least checking email once or twice or at least 3 times in a game, than those from other income levels. 


\begin{tabular}{|c|c|c|c|c|c|}
\hline & 0 & 1 & 2 & 3 & NR \\
\hline \multicolumn{6}{|c|}{ By Gender } \\
\hline Female & $38.7 \%$ & $24.7 \%$ & $21.5 \%$ & $11.8 \%$ & $3.2 \%$ \\
\hline Male & $47.6 \%$ & $24.8 \%$ & $16.6 \%$ & $8.1 \%$ & $2.9 \%$ \\
\hline \multicolumn{6}{|c|}{ By Age } \\
\hline $18-29$ years & $14.0 \%$ & $42.1 \%$ & $21.1 \%$ & $22.8 \%$ & $0.0 \%$ \\
\hline 30-39 years & $29.1 \%$ & $27.2 \%$ & $31.1 \%$ & $9.7 \%$ & $2.9 \%$ \\
\hline 40-49 years & $53.9 \%$ & $20.6 \%$ & $11.8 \%$ & $8.8 \%$ & $4.9 \%$ \\
\hline $50-59$ years & $59.1 \%$ & $19.4 \%$ & $15.1 \%$ & $3.2 \%$ & $3.2 \%$ \\
\hline 60 or older & $75.6 \%$ & $17.8 \%$ & $2.2 \%$ & $2.2 \%$ & $2.2 \%$ \\
\hline \multicolumn{6}{|c|}{ By Household Income } \\
\hline No answer & $62.5 \%$ & $20.3 \%$ & $10.9 \%$ & $3.1 \%$ & $3.1 \%$ \\
\hline Under $\$ 50,000$ & $17.9 \%$ & $28.6 \%$ & $25.0 \%$ & $28.6 \%$ & $0.0 \%$ \\
\hline$\$ 50,000-$ & & & & & \\
\hline$\$ 99,999$ & $37.3 \%$ & $32.2 \%$ & $13.6 \%$ & $13.6 \%$ & $3.4 \%$ \\
\hline$\$ 100,000-$ & & & & & \\
\hline$\$ 199,999$ & $41.7 \%$ & $22.7 \%$ & $25.8 \%$ & $8.3 \%$ & $1.5 \%$ \\
\hline$\$ 200,000-$ & & & & & \\
\hline$\$ 349,999$ & $53.5 \%$ & $26.8 \%$ & $11.3 \%$ & $7.0 \%$ & $1.4 \%$ \\
\hline$\$ 350,000+$ & $47.8 \%$ & $21.7 \%$ & $15.2 \%$ & $4.3 \%$ & $10.9 \%$ \\
\hline Grand Total & $45.5 \%$ & $24.8 \%$ & $17.8 \%$ & $9.0 \%$ & $3.0 \%$ \\
\hline
\end{tabular}

As shown in Table 4, 41.3 percent of those earning $\$ 350,000$ or more checked email at least 3 times in a game. Chi-square analysis of these categorical data has shown the significance of individual characteristics of age, gender, and household income. This difference in email usage patterns is reflected in the Table 4.

Additional findings include:

-Access to team website appeared to be the least popular, with only $15.8 \%$ of fans reporting the Website access at least one time during the games.

-Fans' age and gender were two important factors in their usage patterns of the digital communication channels: The younger ( $<40$ years old) has reported the higher level of social media access, and female fans reported more access to social media during the game than male fans.

-About one third (31.7\%) of the fans were satisfied with the speed and quality of email checking services provided by the team during the game.

-About the same proportion of fans was satisfied with the data downloading (28.8\%) and data uploading (27.8\%) during the games.

- The number of years being a season ticket holder was negatively correlated with the extent of social media access, including a correlation of -0.225 with posting to Instagram or Snapchat, a correlation of -0.199 with accessing team mobile app, and a correlation of -0.176 with posting on Twitter and Facebook.

\begin{tabular}{|l|l|l|l|l|l|}
\hline \multicolumn{5}{|c|}{ Table 4: Frequency of Email Checking } \\
\hline & 0 & 1 & 2 & 3 & NR \\
\hline \multicolumn{5}{|c|}{ By Gender } \\
\hline Female & $32.3 \%$ & $23.7 \%$ & $30.1 \%$ & $10.8 \%$ & $3.2 \%$ \\
\hline Male & $17.9 \%$ & $23.8 \%$ & $25.4 \%$ & $30.0 \%$ & $2.9 \%$ \\
\hline \multicolumn{5}{|c|}{ By Age } \\
\hline $18-29$ years & $26.3 \%$ & $22.8 \%$ & $26.3 \%$ & $24.6 \%$ & $0.0 \%$ \\
\hline $30-39$ years & $8.7 \%$ & $23.3 \%$ & $32.0 \%$ & $33.0 \%$ & $2.9 \%$ \\
\hline $40-49$ years & $25.5 \%$ & $23.5 \%$ & $23.5 \%$ & $22.5 \%$ & $4.9 \%$ \\
\hline $50-59$ years & $23.7 \%$ & $22.6 \%$ & $23.7 \%$ & $26.9 \%$ & $3.2 \%$ \\
\hline 60 or older & $28.9 \%$ & $28.9 \%$ & $26.7 \%$ & $13.3 \%$ & $2.2 \%$ \\
\hline \multicolumn{5}{|c|}{ By Household Income } \\
\hline No answer & $28.1 \%$ & $28.1 \%$ & $15.6 \%$ & $25.0 \%$ & $3.1 \%$ \\
\hline $\begin{array}{l}\text { Under } \\
\text { \$50,000 }\end{array}$ & $35.7 \%$ & $28.6 \%$ & $25.0 \%$ & $10.7 \%$ & $0.0 \%$ \\
\hline $\begin{array}{l}\text { \$50,000- } \\
\text { \$99,999 }\end{array}$ & $28.8 \%$ & $13.6 \%$ & $27.1 \%$ & $27.1 \%$ & $3.4 \%$ \\
\hline $\begin{array}{l}\text { \$100,000- } \\
\$ 199,999\end{array}$ & $22.7 \%$ & $24.2 \%$ & $31.1 \%$ & $20.5 \%$ & $1.5 \%$ \\
\hline $\begin{array}{l}\$ 200,000- \\
\text { \$349,999 }\end{array}$ & $9.9 \%$ & $29.6 \%$ & $29.6 \%$ & $29.6 \%$ & $1.4 \%$ \\
\hline$\$ 350,000+$ & $6.5 \%$ & $17.4 \%$ & $23.9 \%$ & $41.3 \%$ & $10.9 \%$ \\
\hline Grand Total & $21.3 \%$ & $23.8 \%$ & $26.5 \%$ & $25.5 \%$ & $3.0 \%$ \\
\hline
\end{tabular}

\subsection{Regression results}

The regression results are displayed in Table 5 below. On Twitter and Facebook posting, all the four digital communications-Instagram/Snapchat posting, email checking, downloading video, and accessing mobile apps are all positively associated with Twitter/Facebook posting at p-values ranging from 0.01 to 0.05 .

For posting on Instagram and Snapchat, the age of sports fans is significant factor $(-0.21 ; \mathrm{p}<0.01)$. This suggests that older fans are less likely to post on Instagram or Snapchat during a game. With regard to email checking during a game, three demographic factors have shown significant effect, including household income $(0.25 ; \mathrm{p}<0.01)$, gender $(0.32$; $\mathrm{p}=0.05)$, and age $(-0.6 ; \mathrm{p}<0.01)$. In addition, fullseason ticket membership is significant $(0.01 ; \mathrm{p}<0.05)$. 
Twitter/Facebook posting is positively associated with email checking $(0.14 ; \mathrm{p}<0.05)$.

\begin{tabular}{|c|c|c|c|}
\hline \multicolumn{4}{|c|}{ Table 5: Regression Results } \\
\hline & $\begin{array}{l}\text { Twitter } \\
\text { Facebook } \\
\text { Posting }\end{array}$ & $\begin{array}{l}\text { Instagram } \\
\text { Snapchat } \\
\text { Posting }\end{array}$ & $\begin{array}{l}\text { Email } \\
\text { checking }\end{array}$ \\
\hline Intercept & $\begin{array}{l}0.30 \\
(0.19)\end{array}$ & $\begin{array}{c}1.04 * * * \\
(0.18)\end{array}$ & $\begin{array}{l}0.56^{* *} \\
(0.25)\end{array}$ \\
\hline MemberYr & $\begin{array}{l}-0.003 \\
(0.01)\end{array}$ & $\begin{array}{l}0.000 \\
(0.01)\end{array}$ & $\begin{array}{l}0.02 * * \\
(0.01)\end{array}$ \\
\hline Website & $\begin{array}{l}0.03 \\
(0.06)\end{array}$ & $\begin{array}{l}-0.003 \\
(0.06)\end{array}$ & $\begin{array}{l}0.11 \\
(0.08)\end{array}$ \\
\hline MobileApp & $\begin{array}{l}0.13^{* *} \\
(0.05)\end{array}$ & $\begin{array}{c}0.07 \\
(0.05)\end{array}$ & $\begin{array}{l}-0.03 \\
(0.07)\end{array}$ \\
\hline DownloadVideo & $\begin{array}{l}0.14^{* *} \\
(0.06)\end{array}$ & $\begin{array}{c}0.07 \\
(0.05)\end{array}$ & $\begin{array}{l}-0.05 \\
(0.07)\end{array}$ \\
\hline Twitter/FB & & $\begin{array}{c}0.49 * * * \\
(0.04)\end{array}$ & $\begin{array}{l}0.14 * * \\
(0.07)\end{array}$ \\
\hline InstaSnap & $\begin{array}{l}0.51 * * * \\
(0.05)\end{array}$ & & $\begin{array}{l}0.08 \\
(0.07)\end{array}$ \\
\hline Email & $\begin{array}{l}0.08^{* *} \\
(0.04)\end{array}$ & $\begin{array}{c}0.04 \\
(0.04)\end{array}$ & \\
\hline FullSeason & $\begin{array}{l}-0.06 \\
(0.09)\end{array}$ & $\begin{array}{l}0.001 \\
(0.09)\end{array}$ & $\begin{array}{l}0.20 \\
(0.12)\end{array}$ \\
\hline Gender & $-0.15(0.1)$ & $\begin{array}{l}-0.16 \\
(0.1)\end{array}$ & $\begin{array}{l}0.32 * * \\
(0.13)\end{array}$ \\
\hline Age & $\begin{array}{l}0.07 \\
(0.04)\end{array}$ & $\begin{array}{c}-0.21 \\
* * *(0.04)\end{array}$ & $\begin{array}{l}-0.16^{* * *} \\
(0.05)\end{array}$ \\
\hline Houselncome & $\begin{array}{l}-0.05 \\
(0.04)\end{array}$ & $\begin{array}{l}-0.01 \\
(0.04)\end{array}$ & $\begin{array}{l}0.25 * * * \\
(0.05)\end{array}$ \\
\hline $\mathrm{N}$ & 388 & 388 & 388 \\
\hline $\operatorname{Adj~} R^{2}$ & 0.381 & 0.416 & 0.124 \\
\hline
\end{tabular}

Standard errors are in parenthesis, ${ }^{*} \mathrm{p}<0.10,{ }^{* *} \mathrm{p}<$ $0.05, * * * \mathrm{p}<0.01$

\section{Discussion}

Our data analysis of the 400 NBA fans' social media use behaviors suggest that fans demonstrated different preference for the available portfolio of digital communication channels. For fans at younger age or who are female, they were more likely to post on Twitter, Facebook, Snapchat or Instagram during a game. Meanwhile, for those who are older or who are male, they tended to check emails more frequently and make SM posting less frequently during a game. Sports consumers are playing a pivotal role in promoting (or negating) a brand, due to the easy sharing of consumer experience within the new dynamic networks of consumers formed through social media. To this end, our study extended this line of research by uncovering the different preferences for different digital communication channels, including the commonly used social media platforms, and suggesting that sports organizations' digital communication strategies should be tailored to specific platforms and specific types of fans to become effective.

Moreover, our study provided empirical evidence to show the usage of social media and other digital communication channels (such as emails and sports team website) by sports' team's fans. When asked about what one benefit would improve the fans' season ticket membership experience, they frequently cited better communication. One member suggested the team to "[s]till improve on communicating about MVP events so we don't miss opportunities to participate," and another member emphasized the timeliness of the online communication such that " $[b] e$ timelier in posting pictures from season ticket holder events and experiences." In some cases, the season ticket holders proposed a combination of multiple communication channels including traditional phone and email and texting. This is reflected in one member's remark:

"More communication or reminders through email or text. I think sometimes I miss things because I saw an email once but then couldn't find it again. Also, I know you've called me to invite me to special events or pre-game events but sometimes I don't answer my phone and I'm not sure if I missed any events."

Our paper contributes to the research of social media in sports by expanding the social media channels from Facebook and Twitter to all the major types of social media platforms (including Facebook, Twitter, Instagram and Snapchat). Moreover, it compares and contrasts the digital communication use behavior by different groups of fans (e.g., age, gender, household income, and member type). The use of social media channels helps maintain a passionate fan base and deepen fan loyalty and involvement, limiting fan discontent and disconnection and competition from multiple entertainment services [29]. Prior studies have investigated the social media use in sports management and showed that sports organizations prefer Facebook over Twitter when engaging stakeholders [11]. By scrutinizing multiple communication channels, our study provides a partial answer explaining why Facebook and Twitter use by some sports organization 
did not yield significant positive outcome on their relationship dialogue [11]. By analyzing the social media use during a game, this study complements prior studies that focus on sports teams' social media use during the off-season [4].

The new contribution of our paper is two-fold: (1) it expands the social media channels from Twitter to all the major types of social and digital media (including Facebook, Twitter, Instagram, SnapChat, websites, instant message) to examine if the value perceived by fans varied by the channels; (2) it provides a contingency view on the conditions where fans prefer one SM channel to another. As a matter of fact, social media is not simply a technology; it represents a context that differs in important ways from traditional (e.g., face-to-face) and other digital (e.g., email) medium of interacting and communicating. As a result, social media is a relatively unexamined type of context that may affect the cognition, affect, and behavior of individuals within organizations online and offline (i.e. online call to action in an arena).

In this paper, we did not intend to test the causeeffect relationships among the factors, but our results suggest that it is important for national sports organizations such as NBA teams to differentiate the role and impact of the various SM platforms when using the social technology to communicate and engage their fans to deepen the relationship building between the sports teams and the fans. A large-scale quantitative study on the effect of sports' fans' social media use and digital communication on their team member renewal will yield promising insights into the sports' team social and digital media strategy. Future research could also look at influencing items factors such as NBA teams' geographic location. The NBA provides an ideal context for such a study given its national and international reach.

\section{Implication and conclusion}

Mobile Internet provides sports organizations with tremendous opportunities to boost the value of sporting events before, during and after live games. The ability of fans to tweet, post, and text is a fundamental part of the digital stadium experience for two main reasons: (1) demographics' changes (Generation Y) and the need to build a fan base, especially for sports which are aging as for baseball, and (2) the desire to compete with Ultra High Definition TV (UHD) or $4 \mathrm{~K}$ penetration in households converting stadium sections into living room with all the comfort from home (fantasy leagues, mini screens, in-seat food delivery).

With technological innovations, social media networks have become essential to the modern business world, and are especially vital for sports firms and athletes. Social media networks are new channels for firms to connect with their audience and establish a social customer relationship. Consumers are becoming pivotal authors of brand stories due to new dynamic networks of consumers and brands formed through social media and the easy sharing of brand experiences in such networks. To this end, sports organizations should not underestimate how fans are using social media during or outside of the gams to post/retrieve information about the sports teams. To meaningfully realize the benefits of $\mathrm{SM}$ as a relational marketing tool, organizations have to ensure that the SM platforms are well integrated into an organization's overall marketing and communications strategy.

In managerial terms, our findings provide guidance to sport marketers on how to retain loyal fans by evoking their desired gratifications. The study gives empirical evidence that social media provides value from fans' perspective. Such empirically driven understanding allows sport marketers to be proactive and use their social media platforms strategically while differentiating between different types of fans' use.

The use of applications on the Wi-Fi network stadiums produces vast amounts of data that offer good opportunities to optimize stadium and teams' operations, making them smarter or more "intelligent". Social media marketing strategies should include: (1) customize digital communications and online marketing initiatives according to different types of fans and based on their social media preference and needs; (2) create a virtual community online by utilizing social media platforms to connect and engage communities of fans and players (i.e. using community hashtags like \#LakersNation) and provide value-added services online and off line in the arena; and (3) design multi-channel digital marketing strategies to deepen customer relationships with season-ticket holders during the off-season where the production of content differs and other forms of interaction are limited. Further research is needed to examine if these findings can be generalized to other SNS and other cultures, as well as to other leagues and team sports.

In a competitive environment, branding sports organization in the digital space has become critical as it also enhances the value of partnerships online (naming rights, sponsorship, endorsements, promoted tweets). The instantaneity of sharing is the added value of a smartphone, offering ubiquity to its user who no longer needs to wait to get home to share information. This logic puts the Internet in stadiums at the forefront of monetization concerns for sports hospitality managers. By multiplying the total number of beneficiaries of this new digital value chain, smart connected products raise major questions: what organizational capacity should stadiums develops in 
order to improve the delivery of their services? What features should the stadiums provide? Should stadiums internalize or outsource? How does stadium management analyze the data produced? We hope that the findings from this exploratory study have laid some foundation for future research to address the open questions in the digital space of professional sports.

\section{References}

[1] Cisco Visual Networking Index: Forecast and Methodology, 2016-2021, Cisco.com

[2] Pew research Center Social Media Fact Sheet, February $5^{\text {th, }} 2018$.

[3] Kaplan, A. M., \& Haenlein, M. "Users of the world, unite! The challenges and opportunities of social media," Business Horizons, 53, 1 (2010), 59-68.

[4] Meng, M.D., Stavros, C. \& Westberg, K. “Implications for team identification,” Sport, Business and Management: An International Journal, 5, 3 (2015), 199 - 217.

[5] Kuzma J., Viv B.l \& Ciaran L. “A Study of the Use of Social Media Marketing in the Football Industry,” Journal of Emerging Trends in Computing and Information Sciences, 5, 10 (2014), October, 728-738.

[6] Tiago T., Tiago F., Faria D, S. \& Couto J. P. "Who is better player? Off-field battle on Facebook and Twitter," Business Horizons, 59 (2016), 175-183.

[7] Abeza G., O’Reilly N. \& Reid I. “Relationship Marketing and Social Media in Sport,” International Journal of Sport Communication, 6, 2 (2013), 120-142.

[8] Stavros C., Meng M., Westberg K. \& Farrely F. "Understanding fan motivation for interacting on social media,” Sport Management Review, 17 (2014), 455-469. [9] Clark S. John \& Maher Jill K. "Exploring the

Relationship between Sport Fan Identification and Addiction to Digital Sports Media,” Journal of Electronic Commerce in Organizations, 14, 4 (2016), 1-12.

[10] Abeza, G., O’Reilly, N., Seguin, B. “Social Media in Relationship Marketing, the Perspective of Professional Sport Managers in the MLB, NBA, NFL, and NHL," Communication \& Sport, (2017).

[11] Abeza, G., O’Reilly, N. “Social media platforms use in building stakeholder relationships: The case of national sport organizations," Journal of Applied Sport Management, 6 (2014), 103-126.

[12] Dick, R. J., \& Turner, B. A. “Are fans and NBA marketing directors on the same page? A comparison of value of marketing techniques," Sport Marketing Quarterly, 1, 6 (2007), 140-146.

[13] Abdourazakou, Y. “Stades connectés aux États-Unis: États des lieux, enjeux et perspectives,” Revue Europeenne de Management du Sport, 41 (2016), 27-50.

[14] Hipke, M. \& Hachtmann, F. “Game-Changer: A Case Study of Social-Media Strategy in Big Ten Athletic
Departments,” International Journal of Sport

Communication, 7 (2014), 516-532.

[15] Berkowitz, S. "Boosted by network, Big Ten reigns supreme in cash,” USA Today. May 15 2013.

[16] Pedersen, P. M. “A commentary on social media research from the perspective of a sport communication journal editor,” Communication \& Sport, 2, 2(2014), 138142.

[17] Pedersen, P. M. “Communication research and the sport industry: An analysis of sport communication scholarship and scholars," Proceeding of Global Sport Business Association Conference, February 10 ${ }^{\mathrm{TH}}$, 2013, Port of Miami, FL.

[18] Williams, J., \& Chinn, S. J. “Meeting relationshipmarketing goals through social media: A conceptual model for sports marketers," International Journal of Sport Communication, 3, 4(2010), 422-437.

[19] Yoshida, M., Gordon, B., Nakazawa, M., \& Biscaia, R. "Conceptualization and measurement of fan engagement: Empirical evidence from a professional sport context,” Journal of Sport Management, 28 (2014), 399-417. [20] McCarthy, J., Rowley, J., Ashworth, C., \& Pioch, E. "Managing brand presence through social media: The case of UK football clubs," Internet Research, 24 (2014), 181-204. [21] Wallace, L., Wilson, J., \& Miloch, K. “Sporting Facebook: A content analysis of NCAA organizational sport pages and Big 12 conference athletic department pages,” International Journal of Sport Communication, 4 (2011), 422-444.

[22] Clavio, G., \& Kian, T. "Uses and gratifications of a retired female athlete's Twitter followers," International Journal of Sport Communication, 3 (2010), 485-500.

[23] Katz, E., \& Foulkes, D. "On the use of the mass media as "escape": Clarification of a concept," Public opinion quarterly, 26, 3 (1962), 377-388.

[24] Ku, Y. C., Chu, T. H., \& Tseng, C. H. “Gratifications for using CMC technologies: A comparison among SNS, IM, and e-mail," Computers in Human Behavior, 29, 1(2013), 226-234.

[25] Rubin, A. M. "Television uses and gratifications: The interactions of viewing patterns and motivations," Journal of Broadcasting \& Electronic Media, 27, 1 (1983), 37-51.

[26] Ruggiero, T. E. "Uses and gratifications theory in the 21st century,” Mass Communication \& Society, 3, 1 (2000), 3-37.

[27] Dolan, R. M. Social Media Engagement Behavior: A Uses and Gratifications Perspective. Doctoral Dissertation, University of Adelaide, 2015.

[28] Raacke, J., \& Bonds-Raacke, J. “MySpace and Facebook: Applying the uses and gratifications theory to exploring friend-networking sites," Cyberpsychology \& behavior, 11, 2 (2008), 169-174.

[29] Magnusen, M., Kim, J. W., \& Kim, Y. K. “A relationship marketing catalyst: The salience of reciprocity to sport organization-sport consumer relationships," European Sport Management Quarterly, 12, 5 (2012), 501-524. 